\title{
Risk Assessment of Transnational Oil Investment Using a Fuzzy Comprehensive Evaluation Method
}

\author{
Haitao Ma ${ }^{1,2, *}$, Zhan Sun ${ }^{1,2,3}$ and Chuanglin Fang 1,2,3 \\ 1 Key Laboratory of Regional Sustainable Development Modeling, Institute of Geographic Sciences and \\ Natural Resources Research, Chinese Academy of Sciences, Beijing 100101, China; maht@igsnrr.ac.cn \\ (H.M.) \\ 2 Institute of Geographic Sciences and Natural Research, Chinese Academy of Sciences, Beijing 100101, \\ China \\ 3 Department of Resources and Environment, University of Chinese Academy of Sciences, Beijing 100049, \\ China; \\ * Correspondence: maht@igsnrr.ac.cn; Tel.: +86-136-1101-9132
}

\begin{abstract}
Oil has become the object of global exploits and fierce competition among the major world powers as it is a key strategic non-renewable resource. Transnational petroleum investment is therefore an important mechanism available to countries and international corporations to control oil resources even though there are numerous inherent uncertainties and risks. A new risk assessment index system is proposed in this paper based on use of the Delphi expert scoring system and fuzzy comprehensive evaluation that aims to minimize the potential risks inherent to multinational petroleum investment. This approach encapsulates political, legal, socioeconomic, and infrastructural factors to develop a technical method that can be used for transnational petroleum investment risk assessment. An evaluation of oil investment risk within a case study area is also presented; results provide reference data that can be applied by national and international oil companies to mitigate risks of transnational oil investment.
\end{abstract}

Keywords: transnational oil investment, risk assessment, Fuzzy-Grey comprehensive evaluation, Delphi expert scoring system, risk factors, evaluation indicators system

\section{Introduction}

Oil is a key non-renewable strategic resource that underlies national economic growth and social development. This commodity has become one of the most important resources globally, influencing economics as well as political and military patterns. Oil is not only a key mineral resource, it is also of strategic importance to national economic security; countries around the world have increasingly been competing for oil resources [1]. The international distribution and consumption of oil resources is unbalanced, however, in part due to economic globalization; the huge demand for oil in developed countries is not commensurate with their resources, and contradictions between regional supply and demand are increasing [2]. This contrasts with the fact that most global oil reserves are in developing countries where petroleum exploration and development technologies remain relatively less advanced and unable to meet the demands of the modern industry [3]. The existence of large-scale oil reserves has meant that the long-term control by the oil industry has been relaxed, actively leading to the injection of foreign capital and the strengthening of international cooperation. The dual competitive nature of oil resources and the development market has created a new situation globally for the sale of petroleum products; indeed, governments around the world have attached an enhanced level of importance to the issue of national energy security [4].

Investments in international oil resources carry extraordinary risks, usually involving transnational factors related to political, cultural, and economic differences. Nevertheless, although the level of overseas investment in oil is rapidly growing, less attention has been afforded to 
investment risk assessment. The limited research that has been carried out in this area is usually focused on two areas, including assessing the risks of oil investment from an economic perspective, encompassing issues to do with situation and income $[5,6]$. These studies are important and valuable as references for economic income and thus investment efficiency. The other main area of research focus has been the risk assessment of oil investment projects, including overseas ventures in production, processing, exploration, and exploitation $[7,8,9]$. These studies are of significant beneficial value to the normal operation of such projects, especially their investors. Transnational oil investment involves more than just economic factors, however, as political, social, and legal issues must also be taken into account. It is therefore necessary to comprehensively identify the risks that may arise in multinational oil operations of this type from multiple angles and all levels. No comprehensive overview of this area is presently available, while numerous problems related to transnational oil investment need to be solved at the national level via political diplomacy. These issues mean that limited evaluation of individual projects is possible, and no overarching universal macro-scale view of this topic has been undertaken. It is therefore critical to perform international oil risk assessments from a multifaceted, comprehensive perspective as well as at the national level. The special strategic significance of this resource and the numerous uncertainties that exist in transnational investment can lead to inestimable losses. A reasonable evaluation index system is therefore critical if we are to comprehensively evaluate the risks of these investments, attain a level of control, and mitigate further losses.

A scientific evaluation approach to control effective risk is clearly required. A range of methods that can be applied to evaluate project risk are available in the existing research and can be divided into two qualitative and quantitative categories. The first of these, qualitative assessment, enables the essential analysis of a research object, most often using the Delphi expert scoring system. In contrast, a series of quantitative evaluations (i.e., "good", "better", "general", and so on) can also be provided by experts applying a range of techniques, including fuzzy comprehensive evaluation, an analytic hierarchy process (AHP), grey evaluation, and decision tree analysis [10-14]. Qualitative and quantitative methods both have inherent advantages and disadvantages; although the first class of approaches require experts to score projects, these methods are simple and data is easy to obtain [10]. Qualitative results are strongly subjective, however, and deviations often occur, while results evaluated using quantitative approaches are relatively more objective and accurate [14]. One disadvantage of these latter methods is that the evaluation process is complex and original data are hard to obtain. A combined approach using both qualitative and quantitative analyses is therefore applied in this study based on expert scoring paired with the fuzzy comprehensive evaluation method. This approach enables the influence of risk factors to be quantified and therefore directly incorporates the various indicators of this probability into the scientific evaluation of international petroleum enterprise investments.

\section{Risk factor analysis}

Overseas oil investment projects are risky activities that can nevertheless be characterized by contingency, diversity, complexity, and controllability factors [15]. Indeed, because of their transnational nature, overseas investments often encompass different political backgrounds, legal systems, economic conditions, and religious cultures, and thus also involve numerous uncertain factors. All such disturbances either have caused, or will lead to, important impacts on transnational oil investment. Building on previous related research, political, policy, and legal risks as well as economic, social, and infrastructural risks are selected here as key indicators for the evaluation of international oil investment risk (Figure 1). 


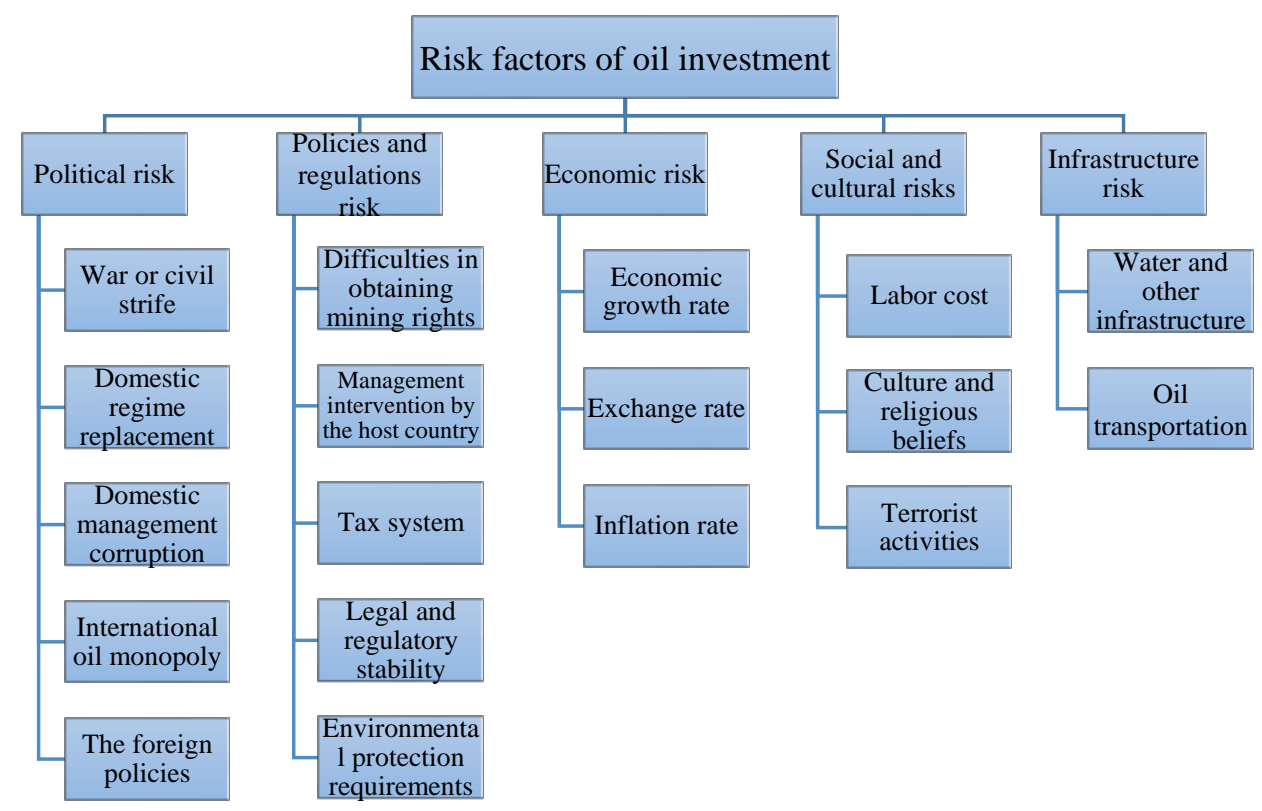

Figure 1. International oil investment risk factors

\subsection{Political risks}

Political risks include changes in the investment environment of a host country during oil investment due to local political instability or other related factors [16]. This category mainly includes risks in relation to domestic regime replacement, management corruption, war or turbulence, modifications to the foreign policies of larger countries, and changes in international oil monopoly structures.

\subsubsection{Domestic regime replacement}

The category of risk mainly refers to changes in state power under non-constitutional procedures. Thus, as an old regime is replaced, a new government will change existing policies as well as aspects of the social, political, and legal system. These changes all mean that the political situation within the country is in turmoil and social order has deteriorated; these will, in turn, influence basic conditions like public security, transportation, and communication, which are all vital to investment and lead to a change in the overall financial environment. Changes will also affect the income of normal businesses and property ownership and will therefore have a negative impact on the oil company investments [17].

\subsubsection{Domestic management and corruption}

As oil enterprises are governed by the state in most cases, investments are closely related to government management. This risk factor is therefore reflected in aspects of whether, or not, a policy is operational, government power, administrative interference in businesses, and the severity of corruption [18]. Thus, if internal corruption is a serious national issue, improper government management can cause economic losses to local oil enterprises as well as reductions in personnel and reputational decline.

\subsubsection{War or civil strife}

This risk factor mainly refers to the probability of war, revolution, and subversion, as well as coups, strikes, civil strife including terrorism, and the activity of local armed forces within an investment host country and the resultant impact of such events [19]. These occurrences can cause serious issues for overseas oil enterprises and may include evacuation and divestment as well as closure and damage, all leading to huge losses. 


\subsubsection{The foreign policies of other countries}

Oil not only provides the energy underlying economic development, but is also a national strategic resource. This means that competition for oil is becoming more and more intense between major countries internationally; indeed, many countries around the world have launched "oil diplomacy" political activities and there is considerable competition between international oil importing, exporting, and transit countries [20]. Government policies in this area exert considerable impact on the international oil market and also lead to numerous uncertainties and risks.

\subsubsection{International oil monopolies}

Western countries dominated most of international oil resources in the aftermath of the Cold War by both diplomatic and economic means, forming large oil companies such as Exxon Mobil and Shell that together controlled $80 \%$ of global assets [21]. In order to maintain this dominance, existing monopolies are bound to intervene and curb access to overseas oil investment in emerging countries.

\subsection{Policy and regulation risks}

Risks in this area refer to the likelihood that laws, regulations, and policy systems in a host country are unsound, unstable, or unregulated for overseas petroleum enterprises. An investment incorporates policy and regulation risks from multiple perspectives, including those of the host and investment countries as well as international organizations.

\subsubsection{Difficulties in obtaining mining rights}

Some countries with oil reserves also have laws that stipulate that natural resources, including minerals, belong to the state. This means that the exploration, production, and development of oil are all governed by government departments, and mining enterprises must be issued with permits [22]. The ownership characteristics of state held petroleum resources therefore make the impact of international oil investments more obvious to national governments, and the difficulty of obtaining mining rights will directly determine exploitation success.

\subsubsection{Management intervention by the host country}

Management intervention by a host country usually happens in order to protect national interests and for the purposes of enabling specific provisions, such as the proportion of workers, limits on the number of devices and the number of foreign personnel. Such actions can influence free business investments and enterprise as well as the management of petroleum exploration and thus income [23].

\subsubsection{Tax systems}

Nations continuously adjust their systems and rates of taxation. In this context, taxes collected on enterprise income and mineral mining significantly affect the economic outputs of foreign-funded enterprises and can lead to financial losses [24].

\subsubsection{Legal and regulatory stability}

Changes to the policies and regulations of host countries and their regions such as those that govern market entry, industrial access, openness, and investment can also cause oil companies to change their investment strategies and behaviors, resulting in economic losses [25].

\subsubsection{Environmental protection requirements}

Numerous countries with oil reserves place restrictions on exploration and exploitation as these processes lead to a range of pollutants including waste gases and water as well as industrial effluents that all negatively impact the local environment [26]. The environmental requirements of local governments as well as public expectations are thus significant pressures on oil companies.

\subsection{Economic risks}


Economic risks encompass the possibility of a gap between the predicted investment income of a project and actual income as a result of various market uncertainties including local economic growth as well as foreign exchange and inflation rates. Economic risks can seriously affect the operation of a project, even interrupt its implementation [27].

\subsubsection{Economic growth rate}

The economic scale and growth trend seen in a host country will exert a significant impact on the size and capacity of national companies and their ability to absorb overseas investment capital. Large oil reserves are mostly resource-based national economic characteristics; in China, as in many countries, the economic development situation is influenced by the international oil price. [28] This means that if the market is buoyant, a shock to international energy prices can cause fluctuations across the whole national economy; sudden marked changes can slow or even stagnate economic growth and cause reduced gains for local oil companies.

\subsubsection{Exchange rate}

Exchange rate risk refers to the possibility that the values of assets and liabilities as well as income and expenditure measured by a foreign currency and the value of local currency expected to generate cash flow in future business activities might fluctuate due to currency exchange rates. As most countries around the world currently utilize floating exchange rate systems, the influence of international political and economic factors as well as fluctuations in international financial market rates will cause frequent currency changes. These variables all lead to a considerable foreign exchange risk on the assets and liabilities of incoming investment enterprises [29].

\subsubsection{Inflation rate}

National market inflation leads to currency devaluation as well as rising prices and interest rates; these changes, in turn, cause corresponding increases in the cost of local investment and financing, and so returns will decrease. Resource-based countries are largely dependent on foreign incoming investment and are therefore economically unstable and likely to be inflationary. As oil companies also often face long investment contract cycles, the rate of inflation in a host country is regarded as a risk factor [30].

\subsection{Social and cultural risks}

Factors in this area mainly include risks that are due to differences in culture and religion. Indeed, if the social and cultural differences between investment and host countries are simply ignored, losses from investment countries will clearly be incurred. The main potential social risks in this area include labor costs, ethnic cultures, and religious beliefs, as well as the likelihood for terrorism in the host country.

\subsubsection{Labor cost}

Overseas investment in an oil project will be impacted by both the quantity and quality of the available labor force [31]. Although this issue can be mitigated during the exploration and exploitation phases as some highly educated and skilled professionals can be sent from the investing countries, the remainder must nevertheless be recruited locally. This will inevitably lead to conflicts between the two workforce components because of cultural differences.

2.4.2 National culture and religious beliefs 
Oil resources often occur in multi-ethnic countries where national composition is very complex. As countries are usually inclined to protect their national interests in terms of policy formulation, operational management, and other aspects, ethnic and cultural differences often result. At the same time, extreme religious organizations can also be present in some countries, which pose a threat to regional stability. Anything that affects national social stability and security also has the potential to influence the operation of oil enterprises [32].

\subsubsection{Terrorist activities}

The existence of terrorist forces can obviously exert a sudden destabilizing impact on energy companies and construction projects, leading to economic losses. The Middle East, Central Asia, and other regions that boast large oil reserves have also experienced a number of political terrorist incidents, such as the "Wu Yi" event. It is generally the case that the expansion of Pan-Islamism has tended to have a negative influence on foreign incoming oil investments [33].

\subsection{Infrastructural risks}

Factors in this area refer to risks incurred within a host country due to backward infrastructural construction including inconvenient traffic conditions that make exploration problematic under local conditions and that mean that oil transportation can be safely guaranteed. This set of risk factors might also cause inefficiencies in exploration, mining, and transportation processes themselves leading to economic losses.

\subsubsection{Water, electricity, transportation, and other infrastructure}

Overseas enterprises that invest and build oil processing infrastructure in other countries are often confronted with problems including inconvenient transportation, disconnected communications, and the lack of water resources. It is therefore necessary for enterprises to sometimes build their own capital in these areas which results in an increase in investment costs [34].

\subsubsection{Oil transportation}

The safe transportation of oil is another key risk index in this area [35]. Two main approaches are presently utilized to move oil between countries, maritime shipping and land pipelines [36]. The latter approach is both safe and stable and can be maintained over long time periods, even though some existing pipelines are currently in a state of disrepair. Transportation capacity and efficiency are also limited in this approach. It is also important to consider the complex geopolitical structure of a host country in this context in order to determine whether laying a pipeline is feasible, as well as its possible length, and export direction. Numerous risk factors affect the safe transportation of oil, including wars, regional conflicts, and other natural environmental variables [37].

\section{Evaluation Methods}

\subsection{General framework}


The disturbance factors that influence transnational oil investment remain unclear. Indeed, it is difficult to quantify these variables as they involve a large number of complex phenomena and interactions between various factors. We therefore chose to apply the Delphi expert scoring system method in tandem with fuzzy comprehensive evaluation to take these characteristics into account; our approach involves the fuzzy comprehensive evaluation of the degree of risk inherent to each element that influences overseas oil investment. Thus, experts were invited to score the potential risk of each factor so that these could be classified and an assessment index system including politics, economics, policies and regulations, society and infrastructure was also constructed. The specific evaluation process followed in this analysis is presented in Figure 2.

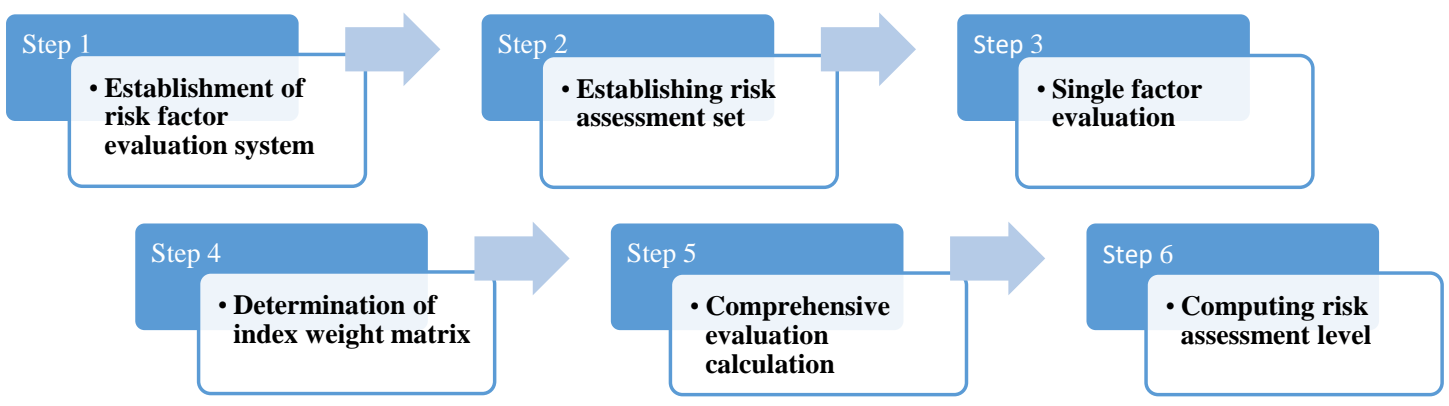

Figure 2. The evaluation method used in this

\subsection{Assessment steps}

The Delphi method and fuzzy comprehensive evaluation approach applied to overseas oil investment risk assessment in this study can be divided into six steps.

\subsubsection{Establishing a risk factor evaluation system}

Five first level risk indicators (i.e., political, economic, legal, social, and infrastructural) were selected for use in this study based on a previous analysis: $U=\left\{u_{-} 1, u_{-}, 2, u_{-} 3, u_{-} 4, u_{-} 5\right\}$. These were utilized alongside 18 second level risk indicators; the specific index system used in this study is summarized in Table 1.

Table 1. An index system for assessing petroleum investment risk

\begin{tabular}{|c|c|c|}
\hline Target layer & Criterion layer & Risk index layer \\
\hline \multirow{17}{*}{ Oil investment risk assessment } & \multirow{5}{*}{ Political risk U1 } & War or civil strife U11 \\
\hline & & Domestic regime replacement U12 \\
\hline & & Domestic management corruption U13 \\
\hline & & International oil monopoly U14 \\
\hline & & Foreign policy changes by other countries U15 \\
\hline & \multirow{4}{*}{$\begin{array}{l}\text { Policy and regulation risk } \\
\text { U2 }\end{array}$} & Difficulty in obtaining mining rights U21 \\
\hline & & Tax system U23 \\
\hline & & Legal and regulatory stability U24 \\
\hline & & Environmental protection requirements U25 \\
\hline & \multirow{3}{*}{ Economic risk U3 } & Economic growth rate U31 \\
\hline & & Foreign exchange risk U32 \\
\hline & & Inflation rate U33 \\
\hline & \multirow{3}{*}{ Social and cultural risks $\mathrm{U} 4$} & National culture and religious beliefs U41 \\
\hline & & Terrorism risk U42 \\
\hline & & Labor capital U43 \\
\hline & \multirow[t]{2}{*}{ Infrastructural risk U5 } & $\begin{array}{l}\text { Water, electricity, transportation and other infrastructure } \\
\text { U51 }\end{array}$ \\
\hline & & Oil transportation method U52 \\
\hline
\end{tabular}

\subsubsection{Establishing a risk assessment set}

As the ultimate aim of fuzzy comprehensive evaluation is to determine the risk level of each index, it is very important to establish a clear grade in each case. The grade of each risk is therefore 
divided into five, encompassing very low, low, general, high, and extremely high; these are assigned numbers as $1,3,5,7,9$, thus: $\mathrm{V}=\left\{v_{1}, v_{2}, v_{3}, v_{4}, v_{5}\right\}=\{1,3,5,7,9\}$.

\subsubsection{Single factor evaluation}

Each risk index was evaluated using the single factor $u_{i}(i=1,2,3 \ldots)$ via expert scoring. A judgment group comprising $\mathrm{N}$ experts was established for this analysis (i.e., 100 research experts were initially selected from a database, provided with a selection of indicators and expert advice, and allowed to perform field scoring) and each provided just one rating, $v_{i}(i=1,2,3 \ldots)$, for each risk indicator, $u_{i}(i=1,2,3 \ldots)$. The fuzzy evaluation vector, $r_{11}=\left\{r_{1}, r_{2}, r_{3}, r_{4}, r_{5}\right\}$, of each risk index, $u_{i}(i=1,2,3 \ldots)$, was then obtained after normalization; the fuzzy evaluation membership matrix of each first level risk index can therefore be obtained as follows:

$$
R_{i}=\left[\begin{array}{ccccc}
r_{11} & r_{12} & r_{13} & r_{14} & r_{15} \\
r_{21} & r_{22} & r_{23} & r_{24} & r_{25} \\
\cdots & \cdots & \cdots & \cdots & \cdots \\
r_{\mathrm{n} 1} & r_{\mathrm{n} 2} & r_{n 3} & r_{n 4} & r_{n 5}
\end{array}\right]
$$

3.2.4 Determining the index weight matrix

An AHP was applied to compare the indexes generated in this study against one another and to generate a judgment matrix. The maximum eigenvalue and corresponding eigenvectors of the matrix $A_{i}=\left\{a_{i 1}, a_{i 2} \ldots a_{i m}\right\}(\mathrm{i}=1,2,3,4,5, \mathrm{~m}=1,2,3 \ldots \mathrm{n})$ were obtained using the software Matlab.

\subsubsection{Comprehensive evaluation calculation}

The fuzzy evaluation matrix, R, and the index weight matrix, A, can be used to evaluate the fuzzy comprehensive evaluation matrix, $\mathrm{M}$, as follows:

$$
\begin{aligned}
M_{i}=R_{i} \times A_{i} & =\left(r_{i 1}, r_{i 2}, r_{i 3}, r_{i 4}, r_{i 5}\right) \times\left[\begin{array}{ccccc}
r_{\mathrm{i} 11} & r_{\mathrm{i} 12} & r_{\mathrm{i} 13} & r_{\mathrm{i} 14} & r_{\mathrm{i} 15} \\
r_{\mathrm{i} 21} & r_{\mathrm{i} 22} & r_{\mathrm{i} 23} & r_{\mathrm{i} 24} & r_{\mathrm{i} 25} \\
\ldots & \ldots & \ldots & \ldots & \ldots \\
r_{\mathrm{in} 1} & r_{\mathrm{in} 2} & r_{i n 3} & r_{i n 4} & r_{i n 5}
\end{array}\right] \\
& =\left(m_{i 1}, m_{i 2}, m_{i 3}, m_{i 4}, m_{i 5}\right) .
\end{aligned}
$$

3.2.6 Computing the risk assessment level

The risk value of a given project can be determined using the evaluation grade set, $\mathrm{U}$, as follows:

$$
U_{i}=M_{i} \times V(i=1,2,3,4,5) .
$$

\section{Case study}

\subsection{Background}

Chinese oil investment in Country $\mathrm{C}$ was used as a case study to perform a model risk assessment in this study. Demand for oil resources has grown rapidly as the economy of China has developed. China became a net oil importer in 1993, and by 2016 crude oil imports had reached 3.81 tons, for the first time surpassing the United States in volume. China is the world's largest net importer of crude oil now, and has a foreign dependency of $65.4 \%$ although imports face a source concentration. In this context, the Middle East and Africa accounted for $51.24 \%$ and $23.7 \%$ of the regional structure of Chinese oil imports in 2016 [38]; this is an issue because of the current political situation in these two regions and because all imports to China pass through the Strait of Hormuz, the Suez Canal, and the Strait of Malacca strategic channels, all easily blocked during the Persian Gulf War [39]. The Chinese Bureau of Petroleum Security considers the current importation situation to 
be extremely unfavorable; thus, in order to ensure energy security, China has implemented an energy importation diversification strategy, actively expanding foreign investment in order to ensure that this goal is attained [39]. However, as the investment environment in Country $C$ is extremely complex, it is necessary to perform an investment risk assessment.

\subsection{Risk assessment results}

We selected 30 well-known experts to provide evaluations who are familiar with the overseas oil investment environment as well as the oil field resources of Country C. These preconditions meant that these individuals were able to accurately determine the degree of influence of different risk factors on oil sector investment within Country C. The expert group included academics from scientific research units, university professors, and oil company senior managers.

Expert analysis and discussion led to the generation of a risk factor judgment matrix for oil investment in Central Asia (Tables 2-6).

Table 2 Political risk judgment matrix

\begin{tabular}{c|c|c|c|c|c}
\hline & $\begin{array}{c}\text { War or } \\
\text { civil strife }\end{array}$ & $\begin{array}{c}\text { Domestic regime } \\
\text { replacement }\end{array}$ & $\begin{array}{c}\text { Domestic } \\
\text { management } \\
\text { corruption }\end{array}$ & $\begin{array}{c}\text { International } \\
\text { oil monopoly }\end{array}$ & $\begin{array}{c}\text { Foreign policy changes } \\
\text { in other countries }\end{array}$ \\
\hline War or civil strife & 1 & 3 & 7 & 2 & 2 \\
\hline $\begin{array}{c}\text { Domestic regime } \\
\text { replacement }\end{array}$ & $1 / 3$ & 1 & 2 & $1 / 2$ & $1 / 3$ \\
\hline $\begin{array}{c}\text { Domestic management } \\
\text { corruption }\end{array}$ & $1 / 7$ & $1 / 2$ & 1 & $1 / 2$ & $1 / 3$ \\
\hline $\begin{array}{c}\text { International oil } \\
\text { monopoly }\end{array}$ & $1 / 2$ & 2 & 2 & 1 & $1 / 2$ \\
\hline $\begin{array}{c}\text { Foreign policy changes } \\
\text { in other countries }\end{array}$ & $1 / 2$ & 3 & 3 & 2 & 1 \\
\hline
\end{tabular}

Table 3 Policy and regulation risk judgement matrix

\begin{tabular}{c|c|c|c|c|c}
\hline & $\begin{array}{c}\text { Difficulty in } \\
\text { obtaining mining } \\
\text { rights }\end{array}$ & $\begin{array}{c}\text { Host country } \\
\text { intervention in } \\
\text { management }\end{array}$ & $\begin{array}{c}\text { Tax system } \\
\text { risk }\end{array}$ & $\begin{array}{c}\text { Legal and } \\
\text { regulatory } \\
\text { stability }\end{array}$ & $\begin{array}{c}\text { Environmental } \\
\text { protection } \\
\text { requirements }\end{array}$ \\
\hline $\begin{array}{c}\text { Difficulty of obtaining mining } \\
\text { rights }\end{array}$ & 1 & 2 & 3 & 7 \\
\hline $\begin{array}{c}\text { Host country } \\
\text { intervention in management }\end{array}$ & $1 / 2$ & 1 & 2 & 2 & 5 \\
\hline Tax system risk & $1 / 3$ & $1 / 2$ & 1 & 2 & 1 \\
\hline Legal and regulatory stability & $1 / 4$ & $1 / 2$ & $1 / 2$ & & 2 \\
\hline $\begin{array}{c}\text { Environmental protection } \\
\text { requirements }\end{array}$ & $1 / 7$ & $1 / 5$ & $1 / 2$ & $1 / 3$ & 3 \\
\hline
\end{tabular}

Table 4 Economic risk judgment matrix

\begin{tabular}{c|c|c|c}
\hline & Economic growth rate & Foreign exchange risk & Inflation rate \\
\hline Economic growth rate & 1 & $1 / 5$ & $1 / 2$ \\
\hline Foreign exchange risk & 5 & 1 & 3 \\
\hline Inflation rate & 2 & $1 / 3$ & 1 \\
\hline
\end{tabular}

Table 5 Social and cultural risk judgment matrix

\begin{tabular}{c|c|cc}
\hline & Labor cost & Terrorist activities & National culture and religious beliefs \\
\hline Labor cost & 1 & $1 / 4$ & $1 / 2$ \\
\hline Terrorist activities & 4 & 1 & 2 \\
\hline National culture and religious beliefs & 2 & $1 / 2$ & 1 \\
\hline
\end{tabular}

Table 6 Infrastructural risk judgment matrix

\begin{tabular}{c|c|c}
\hline & $\begin{array}{c}\text { Water, electricity, transportation } \\
\text { and other infrastructure }\end{array}$ & Oil transportation method \\
\hline $\begin{array}{c}\text { Water, electricity, transportation, and other } \\
\text { infrastructure }\end{array}$ & 1 & $1 / 5$ \\
\hline Oil transportation method & 5 & 1 \\
\hline
\end{tabular}


The maximum eigenvector for each matrix was calculated and then normalized to obtain an index weight (Table 7). The data presented in Table 2 show that the weighting for war or turmoil is largest, while the relative impact of the foreign policy of another country is the second most significant. In contrast, in terms of policy and legal risks (Table 3), the difficulty of obtaining mining rights is considered the most significant, followed by interventions by the host country in operations, while in terms of economic risks (Table 4), experts considered the importance of foreign exchange to be most important. Terrorism was considered the most important component of social risk (Table 5), while the method of oil transportation was thought most critical in terms of infrastructural risks (Table 6).

Table 7 Overall index weighting of risk factors

\begin{tabular}{c|cc}
\hline Criterion layer & Risk index layer & Weight \\
& War or civil strife U11 & 0.4012 \\
Political risk & Domestic regime replacement U12 & 0.1070 \\
& Domestic management corruption U13 & 0.0682 \\
& International oil monopoly U14 & 0.1658 \\
& Foreign policies of other countries U15 & 0.2578 \\
\hline Policy and & Difficulty in obtaining mining rights U21 & 0.4346 \\
regulation risk & Management intervention by the host country U22 & 0.2479 \\
& Tax system risk U23 & 0.1482 \\
\hline \multirow{2}{*}{ Economic risk } & Legal and regulatory stability U24 & 0.1148 \\
& Environmental protection requirements U25 & 0.0546 \\
\hline Social and & Economic growth rate GDP U31 & 0.1220 \\
cultural risks & Foreign exchange risk U32 & 0.6483 \\
\hline Infrastructural & Inflation rate U33 & 0.2297 \\
risk & National culture and religious beliefs U41 & 0.1428 \\
\hline
\end{tabular}

A fuzzy subordinate matrix encompassing the five first level indexes for politics, law, economy, society, and infrastructural risk was then obtained on the basis of scores for each risk grade, as follows:

$$
\begin{aligned}
R_{1} & =\left[\begin{array}{llllc}
0.175 & 0.133 & 0.225 & 0.392 & 0.075 \\
0.117 & 0.358 & 0.208 & 0.258 & 0.058 \\
0.075 & 0.417 & 0.425 & 0.083 & 0 \\
0.075 & 0.492 & 0.300 & 0.133 & 0 \\
0.050 & 0.492 & 0.300 & 0.158 & 0
\end{array}\right] ; \\
R_{2} & =\left[\begin{array}{ccccc}
0 & 0.083 & 0.175 & 0.683 & 0.058 \\
0 & 0.192 & 0.100 & 0.650 & 0.058 \\
0 & 0.142 & 0.417 & 0.442 & 0 \\
0 & 0.292 & 0.117 & 0.400 & 0.192 \\
0.133 & 0.183 & 0.367 & 0.258 & 0.058
\end{array}\right] ; \\
R_{3} & =\left[\begin{array}{ccccc}
0 & 0.283 & 0.408 & 0.308 & 0 \\
0.075 & 0.050 & 0.467 & 0.333 & 0.075 \\
0.075 & 0.100 & 0.408 & 0.342 & 0.075
\end{array}\right] \\
R_{4} & =\left[\begin{array}{ccccc}
0.200 & 0.242 & 0.233 & 0.325 & 0 \\
0.058 & 0.525 & 0.217 & 0.083 & 0.117 \\
0.050 & 0.108 & 0.300 & 0.300 & 0.242
\end{array}\right] \\
R_{5} & =\left[\begin{array}{lllll}
0.117 & 0.408 & 0.342 & 0.133 & 0.000 \\
0.150 & 0.392 & 0.133 & 0.325 & 0
\end{array}\right] .
\end{aligned}
$$

The fuzzy membership vectors and the weight of each index multiplication therefore include: 


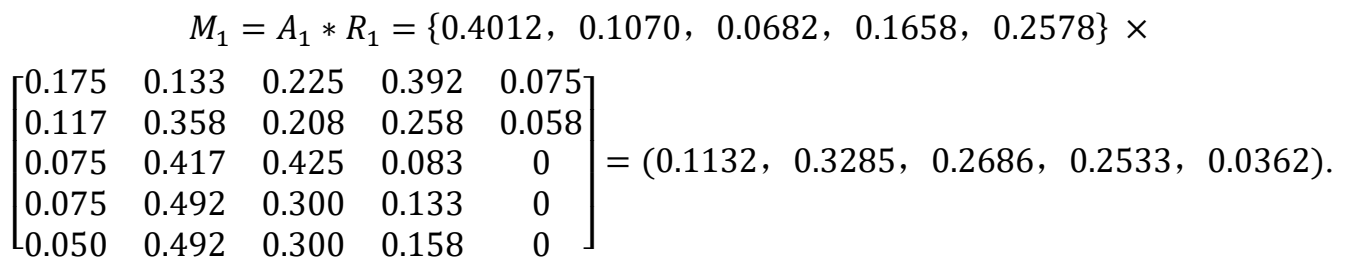

The equation above shows that the political risk of oil investment in Country C encapsulates a $3.62 \%$ very high risk probability, a $25.33 \%$ high risk probability, a $26.86 \%$ general risk probability, a $32.85 \%$ low risk probability, and a $11.32 \%$ very low risk probability. Similarly:

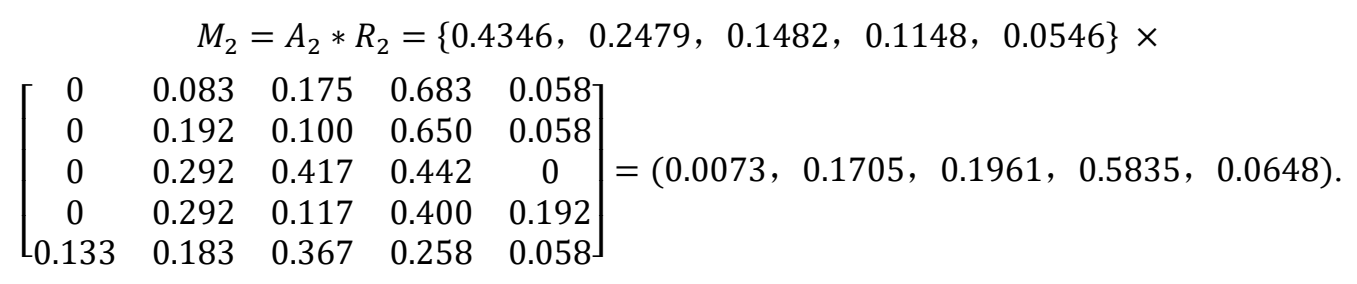

This expression reveals that the policy and regulation risk of oil investment in Country C encompasses a $6.48 \%$ very high risk probability, a $58.35 \%$ high risk probability, a $19.61 \%$ general risk probability, a $17.05 \%$ low risk probability, and a $0.73 \%$ very low risk probability. Similarly:

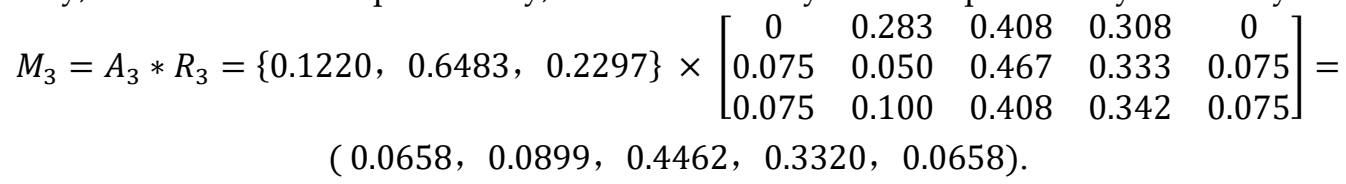

This expression reveals that the economic risk of oil investment in Country $\mathrm{C}$ includes a $6.58 \%$ very high risk probability, a $33.20 \%$ high risk probability, a $44.62 \%$ general risk probability, a $8.99 \%$ low risk probability, and a $6.58 \%$ very low risk probability. Similarly:

$$
\begin{aligned}
& M_{4}=A_{4} * R_{4}=\left\{\begin{array}{lll}
0.1428, & 0.5715, & 0.2857
\end{array}\right\} \times\left[\begin{array}{ccccc}
0.200 & 0.242 & 0.233 & 0.325 & 0 \\
0.058 & 0.525 & 0.217 & 0.083 & 0.117 \\
0.050 & 0.108 & 0.300 & 0.300 & 0.242
\end{array}\right]= \\
& (0.0760,0.3655,0.2430,0.1796,0.1360) \text {. }
\end{aligned}
$$

This expression reveals that the social risk of oil investment in Country C includes a $13.60 \%$ very high risk probability, a $17.96 \%$ high risk probability, a $24.30 \%$ general risk probability, a $36.55 \%$ low risk probability, and a $7.60 \%$ very low risk probability. Finally:

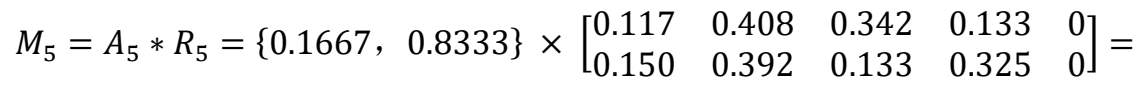

$$
\begin{aligned}
& (0.1445,0.3947,0.1678,0.2930,0.000) \text {. }
\end{aligned}
$$

This expression reveals that the infrastructural risk of oil investment in Country $\mathrm{C}$ includes a zero very high risk probability, a $29.30 \%$ high risk probability, a $16.78 \%$ general risk probability, a $39.47 \%$ low risk probability, and a $14.45 \%$ very low risk probability.

A risk membership matrix of each first-order factor can be obtained from these results, as follows:

$$
\mathrm{R}=\left[\begin{array}{l}
M_{1} \\
M_{2} \\
M_{3} \\
M_{4} \\
M_{5}
\end{array}\right]=\left[\begin{array}{lllll}
0.1132 & 0.3285 & 0.2686 & 0.2533 & 0.0362 \\
0.0073 & 0.1705 & 0.1961 & 0.5835 & 0.0648 \\
0.0658 & 0.0899 & 0.4462 & 0.3320 & 0.0658 \\
0.0760 & 0.3655 & 0.2430 & 0.1796 & 0.1360 \\
0.1445 & 0.3947 & 0.1678 & 0.2930 & 0.0000
\end{array}\right] .
$$

Thus, the degree of risk in the comment set, $\mathrm{V}$, can be quantified, and the final risk assessment of each factor obtained. 
Political risk:

$$
U_{1}=M_{1} \times \mathrm{V}=4.5406 .
$$

Policy and regulation risk:

$$
U_{2}=M_{2} \times \mathrm{V}=6.1670 .
$$

Economic risk:

$$
U_{3}=M_{3} \times \mathrm{V}=5.4827 .
$$

Social risk:

$$
U_{4}=M_{4} \times \mathrm{V}=4.8687 .
$$

Infrastructural risk:

$$
U_{5}=M_{5} \times \mathrm{V}=4.2186 .
$$

These results mean that the final level of risk can be sorted for Country C, as follows:

$$
U_{2}>U_{3}>U_{4}>U_{1}>U_{5}
$$

In this risk classification, a value of 1 represents an extremely low risk, while 9 represents an extremely high risk, and the risk grade within the interval gradually rises. These evaluation results reveal that $7>U_{2}>U_{3}>5>U_{4}>U_{1}>U_{5}>3$; this sequence implies that the infrastructural risk of investing in the oil industry in Country $C$ is the lowest (4.2186), within the low risk index, while indexes for social (4.8687) and policy and regulation factors (4.5406) are both close to 5, within the general low risk category. The economic risk (5.4827) index value, however, is greater than 5, within the general category of high risk. These data imply that foreign enterprises should pay close attention to changes in international currency exchange rates as well as the economic situation within Country $\mathrm{C}$, taking economic market changes into account to ensure the safety of their investments. Finally, results show that the legal risk index (6.1670) falls between 6 and 7, within the category of high risk; thus, overseas enterprises should take full account of their contract terms during the investment process to avoid legal pitfalls, while at the same time perfecting a bilateral legal system, paying close attention to changes in host country policies, and making adequate preparations to avoid losses. Although the social and political risks of investment appear low, it will nevertheless be important to pay attention to cultural differences between foreign investors and the host country as cooperation should involve mutual understanding in ways of thinking as well as in values, habits, customs, and culture. This will mitigate any ethnic prejudice and inherent discrimination to create a good working atmosphere of mutual respect and common ground enabling the mutual exchange of the necessary products.

\section{Conclusions}

As overseas oil investment activities have increased, risk assessments have become more important. Petroleum enterprises should strengthen their research base on the various investment risks that are inherent to host countries in this context. This will be necessary to not only predict longterm future trends, but also to understand these changes from a number of perspectives. The research presented in this paper is therefore likely to provide an important reference for overseas oil investment risk management and control. A novel risk evaluation system for transnational petroleum investment is developed and systematically evaluated in this study. The conclusions of this research are outlined below. 
(1) A comprehensive system for evaluating the risks involved in transnational oil investment is presented in this study. The five main kinds of risk faced by enterprises during these kinds of oil investment include political, policy and regulation, economic, social, and infrastructural; each of these large-scale categories is subdivided here into 18 risk indicators across two levels. This approach enables the comprehensive, scientific, and objective evaluation of the risks involved in transnational oil investment and will provide a reference for oil companies to use in their investment decisions.

(2) A method to quantify the risk of overseas oil investment is designed in this study using the Delphi method in combination with fuzzy comprehensive evaluation. Although the data sources used here are mainly based on expert judgments, and therefore encapsulate a certain degree of subjectivity that might influence assessment accuracy, this approach is nevertheless comprehensive in that it combines both qualitative and quantitative methods. It is important to note that, of the two, quantitative outputs will be more scientific and accurate and therefore should be more reliable in the context of oil investment decisions.

(3) The evaluation results presented here can contribute to transnational oil investment decision-making. As economic globalization continues apace, the international development of oil enterprises also accelerates, and thus accurate risk assessments are particularly important. Developing a scientific basis for these assessments can assist oil enterprises to accurately understand risks, ensure the rationality and feasibility of target planning, and enable the formulation of reasonable mitigation measures. This approach is likely to act as a reference enabling national and international companies to manage oil investment risk.

\section{References}

1. Su, Meirong, et al. ENA-based evaluation of energy supply security: Comparison between the Chinese crude oil and natural gas supply systems. Renewable E Sustainable Energy Reviews 2017, $72,888-899$.

2. Haimes, Yacov Y. Risk Modeling, Assessment, and Management. John Wiley E Sons, 2005.

3. Askari, Hossein, and N. Krichene. An oil demand and supply model incorporating monetary policy. Energy 2010, 35(5), 2013-2021.

4. Hughes, Robert T. "Expert judgement as an estimating method." Information $\mathcal{E}$ Software Technology 1996, 38(2), 67-75.

5. He, Yanan, S. Wang, and K. K. Lai. "Global economic activity and crude oil prices: A cointegration analysis." Energy Economics 2010, 32(4), 868-876.

6. Liu, Hu Chen, L. Liu, and N. Liu. Risk evaluation approaches in failure mode and effects analysis: A literature review. Expert Systems with Applications 2013, 40(2), 828-838.

7. Li, Hui, et al. Assessing Risk in Chinese Shale Gas Investments Abroad: Modelling and Policy Recommendations. Sustainability 2016, 8(8), 708.

8. Jinjarak, Yothin. Foreign direct investment and macroeconomic risk. Journal of Comparative Economics 2007, 35(3), 509-519.

9. Zhu, Lei, Z. X. Zhang, and Y. Fan. An Evaluation of Overseas Oil Investment Projects Under Uncertainty Using a Real Options Based Simulation Model. Ssrn Electronic Journal 2011.

10. Li, Hui, et al. Sustainability Assessment of Refining Enterprises Using a DEA-Based Model. Sustainability 2017, 9(4), 620-635.

11. Zhang, Xiao Chuan, and S. Y. Wang. Comprehensive Evaluation of Water Resources in Tongliao 
Agricultural Irrigation Area Based on AHP. Applied Energy Technology 2017.

12. Liu, Si Feng, and N. M. Xie. New grey evaluation method based on reformative triangular whitenization weight function. Journal of Systems Engineering 2011, 26(2), 244-250.

13. Qu, Y., et al. Boosted decision tree analysis of surface-enhanced laser desorption/ionization mass spectral serum profiles discriminates prostate cancer from noncancer patients. Clinical Chemistry 2002, 48(10), 1835-1843.

14. Zhang, H., and G. Liu. The application of AHP for determining indicator weight in oil/gas security assessment. Natural Gas Industry 2006, 26(4), 135-137.

15. Osabutey, D, et al. Analysis of Risk Management Practices in the Oil and Gas Industry in Ghana. Case Study of Tema Oil Refinery (Tor). European Journal of Business E Management 2013.

16. Busse, Matthias, and C. Hefeker. Political Risk, Institution and Foreign Direct Investment. European Journal of Political Economy 2005, 23(2), 397-415.

17. Stephens, Jennie C., E. J. Wilson, and T. R. Peterson. Socio-Political Evaluation of Energy Deployment (SPEED): An integrated research framework analyzing energy technology deployment. Technological Forecasting \& Social Change 2008, 75(8), 1224-1246.

18. Bo, Rothstein, and D. Eek. Political Corruption and Social Trust. Social Science Electronic Publishing 2009, 21(1), 81-112.

19. Bayulgen, Oksan. Foreign Investment and Political Regimes: Political Risks in Oil Investments: A History of Antagonistic Interdependence Between Companies and Host-Governments. Perspective on Politics 2010, 10(2), 539-541.

20. Alexander, Van De Putte, D. F. Gates, and A. K. Holder. Political risk insurance as an instrument to reduce oil and gas investment risk and manage investment returns. Journal of World Energy Law E Business 2012, 5(4), 284-301.

21. Wagner, Daniel. A new world for political risk investment insurance. Risk management society publishing Inc. 1994 v41.n10.

22. Jensen, Nathan M., E. Malesky, and S. Weymouth. Unbundling the Relationship between Authoritarian Legislatures and Political Risk. British Journal of Political Science 2014, 44(3), 655684.

23. Cheon, A., and J. Urpelainen. Escaping Oil's Stranglehold: When Do States Invest in Energy Security? Journal of Conflict Resolution 2014, 59(6).

24. Cherp, Aleh, and J. Jewell. The concept of energy security: Beyond the four As. Energy Policy 2014, 75, 415-421.

25. Haufler, Andreas, and G. Schjelderup. Corporate Tax Systems and Cross Country Profit Shifting. Norwegian School of Economics and Business Administration, 1999, 306-325.

26. Seyed, Jozi Ali, and P. A. Amaneh. Health-safety and environmental risk assessment of power plants using multi criteria decision making method. Chemical Industry $\mathcal{E}$ Chemical Engineering Quarterly 2011, 17(4), 437-449.

27. Pongsakdi, Arkadej, et al. Financial risk management in the planning of refinery operations. International Journal of Production Economics 2006, 103(1), 64-86.

28. Nakhle, Carole. Petroleum Taxation 2008.

29. Bai, Sijun. The Development of Domestic and Overseas Modern Project Management Discipline Systems. World Sci-tech R \& D 2007, 29(1), 81-83.

30. Prevost, Andrew K., L. C. Rose, and G. Miller. Derivatives Usage and Financial Risk 
Management in Large and Small Economies: A Comparative Analysis. Journal of Business Finance $\mathcal{E}$ Accounting 2010, 27, 733-759.

31. Rezaian, Sahar, and S. A. Jozi. Health- Safety and Environmental Risk Assessment of Refineries Using of Multi Criteria Decision Making Method. Apcbee Procedia 2012, 3(8), 235-238.

32. Zhang, Guomin, and P. X. W. Zou. Fuzzy Analytical Hierarchy Process Risk Assessment Approach for Joint Venture Construction Projects in China. Journal of Construction Engineering $\mathcal{E}$ Management 2007, 133(10), 771-779.

33. Song, Changming, and C. Li. Relationship between Chinese and International Crude Oil Prices: A VEC-TARCH Approach. Mathematical Problems in Engineering 2015, 155(1), A2968.

34. Lee, Ming Chang. Information security risk analysis methods and research trend: AHP and Fuzzy comprehensive method. International Journal of Computer Science E Information Technology 2014, 6, 29-45.

35. Fang, Wei, Y. L. Lei, and A. N. Hai-Zhong. VIEWS ON GLOBAL COOPERATION IN OIL-GAS RESOURCES. Resources $\mathcal{E}$ Industries 2011.

36. Langevin, D., et al. Crude oil emulsion properties and their application to heavy oil transportation. Oil \& Gas Science E Technology 2004, 59, 511-521.

37. Gartrell, Anthony, W. R. Bailey, and M. Brincat. A new model for assessing trap integrity and oil preservation risks associated with postrift fault reactivation in the Timor Sea. Aapg Bulletin 2006, 90(12), 1921-1944.

38. Petroleum, British. BP Statistical Review of World Energy - June 2017. https://www.bp.com/en/global/corporate/energy-economics/statistical-review-of-world-energy.html

39. Houser, Trevor. The Roots of Chinese Oil Investment Abroad. Asia Policy 2008, 5(1), 141-166. 